\title{
Job Motivation and its Relationship With Sexual Attitude Among Iranian Sex Workers
}

\author{
Jamileh Malakouti', Mojgan Mirghafourvand ${ }^{2}$, Azizeh Farshbaf-Khalili' ${ }^{2}$, Tayebeh Azadi ${ }^{3 *}$, Babak Darabi $^{4}$
}

\begin{abstract}
Objectives: The prevalence of high-risk behaviors among different parts of society has attracted attentions to prostitution as one of the most important current problems. This study was carried out to determine the job motivation and its relationship with sexual attitude of sex workers in west of Iran during 2015.

Materials and Methods: This cross-sectional study was conducted on 173 prostitutes. All eligible female prostitutes had a record in state welfare offices, health care centers and drug rehabilitation centers and also street prostitutes sampling was performed through snowball sampling method. Data were collected using socio-demographic, job motivation and Brief Sexual Attitudes Scale (BSAS) questionnaires and were analyzed by using descriptive statistical methods and Kruskal-Wallis test.

Results: The average age of first sexual intercourse and entry into prostitution was 19.1 and 24.3 years, respectively. The mean (SD) score of attitude was 59.8 (4.3). Making money was stated as the main reason for sexual intercourse by the majority of cases (65.9\%), while less than half of them pointed to poor family economic condition as the reason for choosing this job. Based on KruskalWallis test, there was a significant relationship between attitude score and questions of one and seven of motivation questionnaire $(P<0.005)$.

Conclusion: Making money due to poverty and poor economic condition was the main job motivation behind prostitution followed by satisfaction of sexual needs. It can be argued that economic factors should be highlighted and more responsibility should be assumed in resolving this issue in the society.

Keywords: Attitude, Motivation, Sexual activity, Sex workers
\end{abstract}

\section{Introduction}

Modern life problems and difficulties force humans into committing actions that endanger their own lives and society. Alcohol consumption and tobacco use, intentional and unintentional injuries, high-risk sexual behaviors and inadequate physical activity have been introduced by the American Centers for Disease Control and Prevention (CDC) as high-risk behaviors (1). Among such behaviors, high-risk sexual behaviors have attracted more attentions in recent years due to their damaging consequences such as unintended pregnancies, infectious diseases and sexually transmitted infections (STIs) (2).

Prostitution, which can be observed in Iran as well, is an immorality which is generally attributed to females (3). Prostitution is defined as the business or practice of engaging in sexual relations in exchange for money (4). According to official sources, 80000 prostitutes live in Iran (5). The prevalence of high-risk behaviors among different parts of society has attracted attentions to prostitution as one of the most important current problems (6). In Iran, street prostitution is the dominant working model of prostitutes, meaning that a prostitution market has not been completely formed in its actual economic sense, and so prostitution demands, income and costs differ from global models (7).

In Iran, the age of entry into prostitution ranges from 16 to 22 which is above the global scale i.e. 14.1 (8), 15.5 to 16.9 years (9). According to studies, however, this age is decreasing in Iran and one should not neglect its prevalence (7). It can be argued, therefore, that the early entry of females into prostitution endangers their personal and social health from both physical and mental perspectives and this can be considered as a great alarm bell. Although prostitution is considered a crime in Iran, a group of socialists regard it as a social harm that seriously needs to be studied from pathological viewpoints (10).

Studies have shown that the first experience of illegitimate sexual intercourse (11), poverty and poor economic condition $(11,12)$ and family disintegration (12) are among gravitating factors towards prostitution.

Being an informed person is not only a sufficient condition to change people's attitude; rather social and cultural factors such as religion, attitudes towards illness, health and risky behaviors, particularly sexual behaviors could affect their attitudes (13). Motivation is influenced by the attitudes and beliefs.

The acceptance of a problem is the first step in solving the problem. On the other hand, recognizing individuals' 
motivations and their socio-economic conditions are the perquisites for developing a health-promoting plan. Each plan to promote people's health requires knowing their level of awareness, attitude and practice. Therefore, this study was carried out to determine the job motivation and its relationship with sexual attitude of sex workers in west of Iran during, 2015.

\section{Materials and Methods}

This cross-sectional and descriptive-analytic study was conducted on 173 female prostitutes after receiving permission from the Ethics Committee of Deputy of Research and Technology at Tabriz University of Medical Sciences (code of ethics: 139430) that eligible women were chosen from records of the Department of Social Welfare, health care and addiction treatment centers, as well as sampling of street prostitutes through snowball method at Kermanshah, Iran 2015.

The inclusion criteria were women with multi sexual partners, literate, willing to participate, aged 15 to 49 years. The exclusion criteria included individual's withdrawal from the study.

This study was a part of a larger study in which the sample size has been calculated on the basis of knowledge and attitudes. In this case, by considering knowledge by error of $5 \%$ and accuracy of 0.1 around the mean $(\mathrm{m}=4.54)$ and $\mathrm{SD}=3.05$, there were 173 samples (14) and based on the attitude by error $5 \%$ and accuracy of 0.1 around the mean $(\mathrm{m}=7.66)$ and $\mathrm{SD}=2.5,41$ people were assessed (15). Because the estimated sample size based on knowledge was higher, the final sample size was considered 173 individuals.

At first, a list of all women known with high-risk sexual behaviors with records in the Department of Social Welfare, Department of Public Places, health centers, and rehabilitation centers as well as street prostitutes by the snowball sampling method (a non-probable sampling method and identification of one sample of the statistical population and questioning them to identify more samples) along with their phone numbers was provided. Then, individual calls were made with them and the objectives of the study were explained. They were also asked to refer to the mentioned centers. In the briefing sessions, the goals and the method of implementation of the project were made clear to all participants and they were assessed in terms of their basic information and inclusion criteria. Finally, the eligible women were enrolled in the study after the completion of an informed consent forms.

The data collection instruments included 3 questionnaires: motivational, Brief Sexual Attitudes Scale (BSAS) and socio-demographic factors. The items of socio-demographic questionnaire included age, education level, family income, marital status, etc. The questionnaire of sex motivation was a researcher-designed instrument developed based on a review of the related literature $(7,11,16$ 20). This questionnaire examined the sex motivation of prostitutes that included 17 four-choice items (never, low, medium and high). The questionnaire of BSAS included
23 questions five-choice items (strongly disagree, disagree, no opinion, agree, strongly). The range of attitude total score is 0 to 100 and higher scores indicate better attitude. After forward and backward translation, the content validity was determined.

The amount of Content Validity Index (CVI) was 0.86 and 0.92 for BSAS and motivation questionnaires, respectively. Also, the amount of content validity ratio (CVR) was 0.82 and 0.90 for BSAS and motivation questionnaires, respectively. The reliability of the instrument was determined through intra-cluster correlation coefficient (ICC) with 95\% CI was 0.99 (0.99-1.0) and 0.99 (0.99-1.0) for BSAS. The mentioned questionnaires were completed by each individual through researcher's guidance in case of problems in completion of the questionnaires by necessary explanations. To keep the data confidential, an anonymous coding method was used for the questionnaires.

Data were analyzed using descriptive statistics (central and dispersion indexes) and normal distribution of quantitative data was evaluated. Also, Kruskal-Wallis test was used to determine the relationship between motivation and sexual attitude. All analyzes were done by using the SPSS software version 21 .

\section{Results}

Totally, 173 female prostitutes were recruited for this study in 2015. The mean (standard deviation) age of participants was 30.3 (7.5) years. About a quarter of women (26.6\%) were divorced and a quarter of them (24.9\%) were married. Less than half of participants $(40.5 \%)$ were high school and $27.2 \%$ university graduates. One-third of the participants' father's (33.5\%) occupations were as worker and the majority of their mothers' jobs (75.7\%) were housewives. Father's education in more than one-quarter of participants (29.5\%) was diploma and the maternal education was primary school in more than one-third (38.7\%). More than half of women $(51.7 \%)$ were once married. One-third of the married women (33.3\%) mentioned their husbands' job as workers and one-third (33.3\%) were unemployed. More than half of women (52.9\%) reported insufficiency of their families' economic situation (Table 1).

About $51.8 \%$ of them had no insurance coverage and about two-thirds of participants (63.4\%) did not have any income source other than sex working. The mean (SD) age of the first illegal sexual intercourse was 19.1 (2.8) years and with extent of 9-30 years. The mean (SD) onset age of prostitution was 24.3 (4.2) years. The frequent first illegal sexual activity was at the ages of $19(15 \%)$ and 20 (16.8\%) years (Table 2 ).

The mean (SD) score of attitude was 59.8 (4.3) from the obtainable range of zero to 100 . Based on Kruskal-Wallis test, there was a significant relationship between attitude score and questions of one and seven of motivational questionnaire $(P<0.005)$. Most women $(65.9 \%)$ mentioned their purpose of sexual activity was finding a source of money for living. About half of the women (45.7\%) reported their financial needs as the reason of staying on this job. Less than half of women $(44.5 \%)$ considered their 
Table 1. Demographic Characteristics of Women Known to Have High Risk Sexual Behavior $(n=173)$

\begin{tabular}{|c|c|}
\hline Demographic & No. (\%) \\
\hline \multicolumn{2}{|l|}{ Age group } \\
\hline$>20$ & $20(11.6)$ \\
\hline $21-31$ & $77(44.5)$ \\
\hline$>31$ & 76 (43.9) \\
\hline Mean (SD) & $30.3(7.5)$ \\
\hline \multicolumn{2}{|l|}{ Education level } \\
\hline Primary school & $7(4.0)$ \\
\hline Guidance school & $26(15.0)$ \\
\hline High school & $23(13.3)$ \\
\hline Diploma & 70 (40.5) \\
\hline Academic & $47(27.2)$ \\
\hline \multicolumn{2}{|l|}{ Number of Children* } \\
\hline 0 & 83 (61.9) \\
\hline $1-2$ & $42(31.3)$ \\
\hline 2 and more & $9(6.7)$ \\
\hline \multicolumn{2}{|l|}{ Father's job } \\
\hline Unemployed & $16(9.2)$ \\
\hline Working & $58(33.5)$ \\
\hline Employee & $49(28.3)$ \\
\hline Free & $50(28.9)$ \\
\hline \multicolumn{2}{|l|}{ Family status } \\
\hline With parents & $119(69.2)$ \\
\hline Stepmother and stepfather & $22(12.8)$ \\
\hline Parents are divorced & $22(12.8)$ \\
\hline Parents dead & $9(5.2)$ \\
\hline \multicolumn{2}{|l|}{ Sufficient income for living costs } \\
\hline Inadequate & 91 (52.9) \\
\hline Less than adequate & $43(25.0)$ \\
\hline Adequate & $38(22.1)$ \\
\hline \multicolumn{2}{|l|}{ Number of marriages } \\
\hline 1 & 89 (51.7) \\
\hline 2 & $39(22.7)$ \\
\hline 3 or more & $9(5.2)$ \\
\hline \multicolumn{2}{|l|}{ Father's education } \\
\hline Illiterate & $18(10.4)$ \\
\hline Primary school & $36(20.8)$ \\
\hline Secondary school & $40(23.1)$ \\
\hline High school \& diploma & $64(37.0)$ \\
\hline Academic & $15(8.7)$ \\
\hline \multicolumn{2}{|l|}{ Marital status ${ }^{\mathrm{a}}$} \\
\hline Single & $35(22.5)$ \\
\hline Married & $43(24.9)$ \\
\hline Divorced & $46(26.6)$ \\
\hline Widow & 34 (19.7) \\
\hline Registered and unregistered concubine & $11(6.4)$ \\
\hline \multicolumn{2}{|l|}{ Husband's education ${ }^{\mathrm{b}}$} \\
\hline Secondary school and lower & 8 (14.9) \\
\hline High school and diploma & $33(61.1)$ \\
\hline Academic & $13(24.1)$ \\
\hline \multicolumn{2}{|l|}{ Husband's Job } \\
\hline Unemployed & $18(33.3)$ \\
\hline Working & $18(33.3)$ \\
\hline Employee & $9(16.7)$ \\
\hline Free & $9(16.7)$ \\
\hline \multicolumn{2}{|l|}{ Occupation of mother } \\
\hline Housewife & $131(75.7)$ \\
\hline Employee & $42(24.2)$ \\
\hline \multicolumn{2}{|l|}{ Maternal education } \\
\hline Illiterate & $29(16.8)$ \\
\hline Primary school & $67(38.7)$ \\
\hline Secondary school & $22(12.7)$ \\
\hline High school and Diploma & 43 (24.9) \\
\hline Academic & $12(6.9)$ \\
\hline \multicolumn{2}{|l|}{ Housing } \\
\hline Rental & $100(58.5)$ \\
\hline Personal & $56(32.7)$ \\
\hline Family home & $15(8.8)$ \\
\hline $\begin{array}{l}\text { The total of frequency (\%) is unregistered in } \\
\text { and registered individuals concubine } 5(2.9) \text {. } \\
\text { Frequency total (\%) is individuals of illit } \\
\text { chool } 4(7.4) \text { and secondary school } 3(5.6) \text {. } \\
\text { Does not include single people. }\end{array}$ & $\begin{array}{l}\text { concubine } \\
1.9) \text { and p }\end{array}$ \\
\hline
\end{tabular}

families' economic hardships as a reason. Some cases (41.6\%) mentioned the reason of staying in this job was their parents' poverty. $22.0 \%$ of the women considered it for sexual satisfaction and sexual needs (Table 3).

\section{Discussion}

According to this study, the following main factors, among different items, were reported by the prostitutes as the major motivations for their entry into or continuing prostitution: earning money, their financial needs, parents' poverty and poor economic conditions of families and satisfaction of sexual needs. Furthermore, they were not revengeful towards males, married women or their own spouses.

Lack of additional income resources, inappropriate job on the part of their spouses or parents and lower income levels were other influential factors of inclination towards prostitution. This means that they had chosen prostitution in order to make sufficient money. Therefore, in their view, prostitution serves as a job for making more money despite the fact that entry into prostitution to live is legally and traditionally an indecent activity in the Iranian outlook.

This study showed that the average age of prostitutes was

Table 2. Characteristics Associated With Sexual High-Risk Behaviors in Women $(n=173)$

\begin{tabular}{lc}
\hline Demographic & No. (\%) \\
\hline Age at first sexual activity (year) & \\
Mean (SD) & $19.1(2.8)$ \\
Age of entry into sexual activity (year) & \\
$\quad$ Mean (SD) & $24.3(4.2)$ \\
Number of sex weekly & \\
1-2 & $62(36.3)$ \\
3 and more & $109(63.7)$ \\
Intercourse times daily & \\
$0-1$ & $11(6.4)$ \\
$2-3$ & $105(61.4)$ \\
$4-5$ & $36(21.1)$ \\
More than 5 & $19(11.1)$ \\
History of sexual abuse in childhood & \\
Yes & $115(67.3)$ \\
No & $56(32.7)$ \\
Employment status & \\
Group & $30(17.6)$ \\
Individual & $140(82.4)$ \\
History of involvement in this job (year) & \\
Mean (SD) & $6.0(5.1)$ \\
Weekly Income (1000 rials) & \\
500-990 & $5(2.9)$ \\
1000-1490 & $15(8.8)$ \\
1500-2000 & $37(21.8)$ \\
More than 2000 & $113(66.5)$ \\
Maximum working time & \\
Morning & $72(42.1)$ \\
Afternoon & $22(12.9)$ \\
Night \& evening & $16(9.3)$ \\
Morning \& evening & $42(24.6)$ \\
During the day & $10(5.8)$ \\
\hline
\end{tabular}


Table 3. Frequency of Motivational Factors and its Relationship With Sexual Attitude in Women With High-Risk Sexual Behavior, $n$ (\%)

\begin{tabular}{|c|c|c|c|c|c|c|}
\hline & Item & Never & Low & Medium & High & $P$ Value \\
\hline 1 & My goal is to get income from sex & 24 (13.9) & $8(4.6)$ & $27(15.6)$ & 114 (65.9) & $0.010^{\mathrm{a}}$ \\
\hline 2 & I do sexual relationship in order to satisfy self-sexual needs & $38(22.0)$ & $24(13.9)$ & $73(42.2)$ & $38(22.0)$ & 0.153 \\
\hline 3 & I attempted to have sex in order to take revenge of men & $149(86.1)$ & $18(10.4)$ & $2(1.2)$ & $4(2.3)$ & 0.496 \\
\hline 4 & I attempted to have sex in order to take revenge of married women & $143(82.7)$ & $1(13.3)$ & $3(1.7)$ & $4(2.3)$ & 0.782 \\
\hline 5 & I have sex in order to take revenge of my wife & $140(80.9)$ & $19(11.0)$ & $3(1.7)$ & $4(2.3)$ & 0.505 \\
\hline 6 & I attempted to have sex because I would be diversity & $78(45.1)$ & $76(43.9)$ & $17(9.8)$ & $2(1.2)$ & 0.845 \\
\hline 7 & A sense of Inferiority made me choose this job & $106(61.3)$ & $53(30.6)$ & $12(6.9)$ & $2(1.2)$ & $0.034^{\mathrm{a}}$ \\
\hline 8 & I entry into this job because poverty of my parents & $52(30.1)$ & $34(19.7)$ & $15(8.7)$ & $72(41.6)$ & 0.074 \\
\hline 9 & I entry into this job because addiction of my wife or my parents & $100(57.8)$ & $42(24.3)$ & $17(9.8)$ & $14(8.1)$ & 0.895 \\
\hline 10 & I went to this job due to family economic hardship & $44(25.4)$ & $28(16.2)$ & 24 (13.9) & $77(44.5)$ & 0.058 \\
\hline 11 & I continue this job due to my addiction to narcotics & $136(78.6)$ & $15(8.7)$ & $16(9.2)$ & $6(3.5)$ & 0.925 \\
\hline 12 & I stay in this job due to my addiction to sexual relations & $79(45.7)$ & $80(46.2)$ & $11(6.4)$ & $3(1.7)$ & 0.242 \\
\hline 13 & I 've been on the job due to my financial needs & $40(23.1)$ & $33(19.1)$ & $21(12.1)$ & $79(45.7)$ & 0.163 \\
\hline 14 & I stay in this job because pleasure and interest & $58(33.7)$ & $78(45.3)$ & $28(16.3)$ & $8(4.7)$ & 0.851 \\
\hline 15 & $\begin{array}{l}\text { I continue this job because the society rejects me for being a sexually active } \\
\text { individual }\end{array}$ & $83(48.5)$ & $63(36.8)$ & $17(9.9)$ & $8(4.7)$ & 0.877 \\
\hline 16 & I stay in this job due to my auto phobia & $106(61.6)$ & $47(27.3)$ & $11(6.4)$ & $8(4.7)$ & 0.897 \\
\hline 17 & $\begin{array}{l}\text { I continue this job due to threats (physical, honor-related, etc.) on the part of } \\
\text { related individuals }\end{array}$ & $109(63.4)$ & 36 (20.9) & $7(4.1)$ & $20(11.6)$ & 0.221 \\
\hline
\end{tabular}

${ }^{a}$ Represents of association demographic characteristics with attitude score with significant level $P<0.05$.

30.3 (7.5), that the most frequent ages of the first illegitimate sexual intercourse ranged from 19 to 20 and prostitution was prevalent between 20 to 30 . This implies that there is a narrow distance between the first illegitimate sexual intercourse and the onset of sexual activity. In this study, $67.3 \%$ of cases had experienced sexual abuse during their childhood and this can be considered as a great health risk for the entry of this type of individuals into prostitution. In our study, there was no history of depression or mental disorder among the studied cases, except a few. The weekly income of more than half of the cases was above 2 million Iranian rails (US\$66) and they mostly worked in the mornings and had sexual intercourse more than 3 times a week. The education of $67.7 \%$ of the cases was diploma or above. According to the results, the most frequent participants in terms of parents' education and job were those whose mothers and fathers' education levels were elementary and slightly-above-elementary, respectively.

This study showed that the scores of sexual attitude of sex workers was in the average range; and with increased sexual attitude, the job motivation was decreased as well. This suggests that with increase confidence of individuals and correction of business objectives can be raised their attitude.

In study by Sharafatipour et al in Tehran-Iran, the most frequent age of the first illegitimate sexual intercourse was 13 and 14 and $74.6 \%$ of cases had experienced the first illegitimate sexual intercourse before 18 (16). In the study by Mirzaie et al in Tehran-Iran (18), the vast majority of prostitutes were 12 to 19 years old and $41.9 \%$ of them were not revengeful.
In a cross-sectional study by Purushottam et al in Mumbai, the mean age of the prostitutes was 26.4 years (12). Bahari et al in a study at Tehran, Isfahan, Shiraz, Kermanshah and Rasht, cities of Iran showed that the highest frequency was related to the age group of 14 to 18 years (19). In a study conducted by Larki et al on 40 prostitutes in Mashhad-Iran, the average age was 27.3 years (21). The above mentioned studies disagree with ours.

In study by Sagtani et al, the prevalence of depression among prostitutes was $82.4 \%$ while it was 5-6 times more in prostitutes with rape and high-risk sexual relations experience, respectively (22). Again, this disagrees with our study which can be attributed to different instruments used for depression diagnosis (in our study it was diagnosed based on individual's own statements).

The study of Madani et al showed that the active working hours of the vast majority of prostitutes was 16 to 24 . However, the average income of street prostitutes in Tehran market was 1920000 Iranian rials (about US\$55) per week. The income level decreased as the age of prostitutes increased (7). Inflation and increased income, which have contributed to the increased income of prostitution, may account for the differences between the study of Madani et al and ours. On the other hand, the shift of working hours from afternoons and nights to mornings may be the result of the active presence of police in those specific hours or the customers' job which requires further investigation. In our study, half of the cases were married or divorced and the vast majority of them had no child. More than half of them lived in families with 3 to 5 members and their parents were alive. In study by Mirzaie et al, the vast majorities of prostitutes were single with junior high school 
education levels and were living in families with 3 to 5 members with their parents (18). Results of study by Bahari et al revealed that the vast majority of prostitutes did not have high school education and $55 \%$ of them were suffering from insecure marital relations. More than $50 \%$ of cases had no job with legitimate income and the most frequent prostitutes (45\%) were cases with illiterate mothers and $30 \%$ of them had mothers with elementary education levels. Regarding their fathers, 32 and 39\% of cases had illiterate and elementary educated fathers, respectively (19). In study by Sharafatipour et al, the highest frequency was related to unmarried participants by $66 \%$ and $45.3 \%$ of street prostitutes lived alone (16). In the study by Larki et al, most of sex workers had high school education or so, their parents' education was at the level of literacy and $90 \%$ of participants were divorced or were widows (21). This implies that the participants' parents had been deprived of cultural-educational services which should have been provided by responsible channels such as educational organizations and mass media.

Our study is compatible with the study of Larki et al but disagrees with other studies. The reason behind this nonconformity may be attributed to the increased prostitution age and decreased illiteracy, which in turn results in increased education.

Regarding parents' and spouses' job conditions, more than $50 \%$ of cases in our study had worker fathers. However, the vast majority of them had housekeeper mothers and more than half of them had jobless or worker spouses. These values indicate that the cases' parents had not had appropriate economic conditions. This has overshadowed their marriage and in turn resulted in the generation of other problems and psycho-social abnormalities. This signifies the importance of parents' education in entering prostitution.

Study by Varvaie et al showed that economic concerns were the main factor of gravitation towards prostitution followed by joblessness, inappropriate job and lack of a strong guardian (11). In a cross-sectional study in Mumbai by Purushottam et al, $43.8 \%$ of prostitutes belonged to lower socio-economic classes. According to the study's cases, poverty and disintegrated families were the main reasons for entry into prostitution (12). Our results are in agreement with those of the above study.

Study by Damari et al showed that by correcting wrong attitudes of each region, attitude of people to donate blood voluntarily increased (23). The result of above study is consistent with the result of the present research.

\section{Conclusion}

In this study, as sampling was conducted only on prostitutes working in Kermanshah-Iran, therefore, it cannot be generalized to other societies. This was a limitation of this study. However, there were other limitations too. For example, samples might not have entered accurate data due to the items' nature. However, this limitation was regulated to some extent by not mentioning the respondents' names and by emphasizing the fact that the responses would be remain confidential. This study used convenience sampling method, which is another limitation that reduces the generalization of results. On the other hand, the subject of this study was not a repetitious, one which can be regarded as its merit. It is recommended that simultaneous studies be conducted on large populations and also among jail resident prostitutes in different societies. However, it is also suggested that similar studies be conducted on other groups of societies, especially younger groups, in order to prevent high-risk behaviors, especially during youth. Preventive actions, including the identification of vulnerable females, supplying their immediate needs in fast social services through organizing and adopting follow-up actions should be done to identify the vulnerable prostitutes.

\section{Ethical Issues}

This study was conducted on female prostitutes after receiving permission from the Ethics Committee of Deputy of Research and Technology at Tabriz University of Medical Sciences (code of ethics: 139430).

\section{Conflict of Interests}

The authors declare no conflict of interests.

\section{Finnacial Support}

This study was supported by Tabriz University of Medical Sciences.

\section{Acknowledgments}

Hereby, we would like to thank the Deputy Research of Tabriz University and Faculty of Nursing and Midwifery, Kermanshah University of Medical Sciences and all the women who patiently assisted us in data collecting.

\section{References}

1. State injury mortality 2000 [cited 2013 December 17]. Available from: http: // www.cdc.gov/.

2. Santelli J, Carter M, Orr M, Dittus P. Trends in sexual risk behaviors, by nonsexual risk behavior involvement, U.S. high school students, 1991-2007. J Adolesc Health. 2009;44(4):372-9. doi: 10.1016/j. jadohealth.2008.08.020.

3. Poor Afkari N. Comprehensive dictionary of psychology - psychiatry. Tehran: Contemporary Culture; 1373.

4. Falahati A. Prostitution and the Heavy Silence of Law. 6th ed. Tehran: Cultural and Social Council for Woman and Family; 2003.

5. Nasirian M, Doroudi F, Gooya M, Sedaghat A, Haghdoost A. Modeling of human immunodeficiency virus modes of transmission in iran. J Res Health Sci. 2012;12(2):81-7.

6. Slusky R. Decreasing high-risk behavior in teens. A theater program empowers students to reach out to their peers. Healthc Exec. 2004;19(1):48-9.

7. Madani M, Raees dana F, Roshanfekr P. Market prostitution women's in Metropolitan Tehran. J ournal of Iranian Social Studies. 2012;6(1):130-53. 
8. Farley M, Cotton J, Lynne S, et al. Prostitution and trafficking in nine countries: an update on violence and post-traumatic stress disorder. Trauma Practice 2003;2(3):33-74.

9. Lowman J. Violence and the outlow status of (street) prostitution in Canada. Violence Against Women. 1996;6(9):101-987.

10. Mehrara A. Basic Social Psychology. Tehran: Mehrdad; 1994.

11. Varvaie A, Niazkhani M, Kolaki H. Analysis of economic factors effective on the tending to the street prostitution and social- police solutions of its prevention. Entezam-E-Ejtemaei 2010;2:125-57. [Persian].

12. Purushottam G, Renuka C, Abhiram M. Sexual behaviour, knowledge, attitude and practices regarding HIV/AIDS amongst female sex workers (FSWs) in red light area of Mumbai city. Int J Med Sci Public Health. 2012;1(2):132-7.

13. Shiferaw Y, Alemu A, Getahun A, Kassa A, Gashaw A. Assessment of knowledge, attitude and risk behaviors towards HIV/AIDS and other sexual transmitted infection among preparatory students of Gondar town, north west Ethiopia. BMC Res Notes. 2011;4:505. doi: 10.1186/1756-0500-4-505.

14. Ramezani F, Malek-Afzali H. Knowledge, attitudes and practices concerning HIV/AIDS among Iranian at-risk sub-populations. East Mediterr Health J 2008;14(1):142-56.

15. Etemad K, Heydari A, Eftekhar A, Kabir M, Sedaghat $\mathrm{M}$. Knowledge and attitude levels in high risk groups about HIV/AIDS and relation with socioeconomic level indicators in Golestan province (2007). J Gorgan Univ Med Sci. 2010(2):63-70.
16. Sharafatipour J. Social and economic characteristics of street women in Tehran city. Social Welfare. 2006;6(22):173-96.

17. Pitts M, Smith A, Grierson J, O’Brien M, Misson S. Who pays for sex and why? An analysis of social and motivational factors associated with male clients of sex workers. Arch Sex Behav. 2004;33(4):353-8.

18. Mirzaie B, Ranjgar B. [The study of social, financial and family condition of the women prostitutes in Tehran]. Andisheh Va Raftar. 2007;1:41-9. [Persian].

19. Bahari R, Golshan Fomani M. Status of social participation among prostitutes (a comparative study in Tehran, Isfahan, Shiraz, Kermanshah and rasht) in 1390. Social Research 2013;6(18):157-78.

20. Central European University. International Policy Fellowship Program. http://www.policy.hu/kalikov/ index.html.

21. Larki M, Tafazoli M, Latifnejad R, Shakeri M, Babaei A. Assessment of perceived educational needs of damaged women in relation with high risk sexual behavior. IJOGI. 2015;17(130):21-31.

22. Sagtani R, Bhanttarai S, Adhikari B, Baral D, Yadav D, Pokharel P. Violence, HIV risk behaviour and depression among female sex worker of eastern Nepal. BMJ Open. 2013;3(6). pii: e002763. doi: 10.1136/bmjopen-2013-002763.

23. Damari B, Torabian S, Magsudlu M, Mohammadi N, Naserbakht M, Gharah Baghian A. The survey of preventive views and beliefs of voluntary blood donation among people in 3 provinces of hormozgan, sistan-baluchestan and Khuzestan. Scientific Journal of Iranian Blood Transfusion Organization. 2006;3(2):133-43.

Copyright (C) 2016 The Author(s); This is an open-access article distributed under the terms of the Creative Commons Attribution License (http://creativecommons.org/licenses/by/4.0), which permits unrestricted use, distribution, and reproduction in any medium, provided the original work is properly cited. 